\title{
A Simple Tool for Assessing Solar and Daylight Access in Urban Canyons
}

\author{
Raphaël Compagnon, Christina Chatzipoulka \\ Haute école d'ingénierie et d'architecture de Fribourg (HEIA-FR) \\ HES-SO // University of Applied Sciences of Western Switzerland
}

\begin{abstract}
A new online tool to assess solar and daylight access over the surfaces enclosing an urban canyon (i.e. building façades and street) is presented. From a limited series of parameters, users can easily describe the orientation and geometry of an urban canyon and precisely define an area of interest for which the calculations have to be performed. By implementing an original calculation method based on stereographic pictures, this tool aims both to demonstrate its capabilities and to serve for architectural and urban planning educational purposes. Its main advantage is that, beside providing numerical indicators (e.g. solar exposure, solar irradiation, sky view factor, daylight sky component) that can take inter-reflections into account, it also allows to visually interpret the results in a rather intuitive manner. The calculation method is available as an open source software package. It can serve to assess solar and daylight access in more complex urban forms.
\end{abstract}

Keywords: urban canyon, solar exposure, solar irradiation, sky view factor, daylight sky component, inter-reflections

\section{Introduction}

In the framework of a recently completed research project, we developed a simple method to quantify solar and daylight access over building envelopes or open spaces located in urban areas (Compagnon et al. 2015, Chatzipoulka et al., 2018). It is based on special types of images that retain only the geometrical information required to compute the incoming solar irradiance or daylight illuminance on the surfaces forming an entire urban masterplan or a subpart of it (e.g. buildings' façades, roofs, streets). These special images, the so-called "multishading masks" and "effective envelope area pictures", are formed as stereographic projections showing the visibility between the surfaces considered and the sky vault. They can be visual interpreted as well as processed to compute solar and daylight quantities on the considered surfaces. The method has been embedded in INDALUX, an open-source, RADIANCEbased software package [RAD, IDLX].

Previously, in order to demonstrate the method and its capabilities, we developed (Compagnon, 2014) an interactive web interface [IBIC] that allows the application of the method for building surfaces in a series of typical settings (e.g. unobstructed vertical façades or tilted planes, and urban canyon's façades and streets) for a dozen of different locations/climates. In this paper, we present a second interactive web tool devoted to urban canyons [UBC] that also incorporates the latest developments of the method, namely its extension to account for inter-reflections. From its home page, the user can specify the dimensions and orientation of the studied urban canyon, and define the precise part of the façade on which the analysis has to be performed. Next, the tool will automatically generate a proper 3D model and apply the programs from the INDALUX package installed on the server. Since this process does not last but few seconds before the results are displayed on a web page, the tool can be easily used repeatedly to observe how the results are affected by varying one or several parameters. Hence, it is well suited for being applied in the teaching context, for instance in architecture or urban studies.

The paper is organised as follows: Section 2 presents the input parameters (required and optional) using a particular urban canyon as a case study example. Section 3 presents the outputs/indicators derived from processing "multishading masks", while Section 4 focuses on those obtained by processing "effective envelope area pictures". 


\section{Defining an urban canyon}

Our tool assumes an infinitely long symmetrical urban canyon (i.e. both façades have the same height). Figure 1 shows the adjustable parameters defining the canyon's orientation and dimensions that can be specified in any unit at any scale.

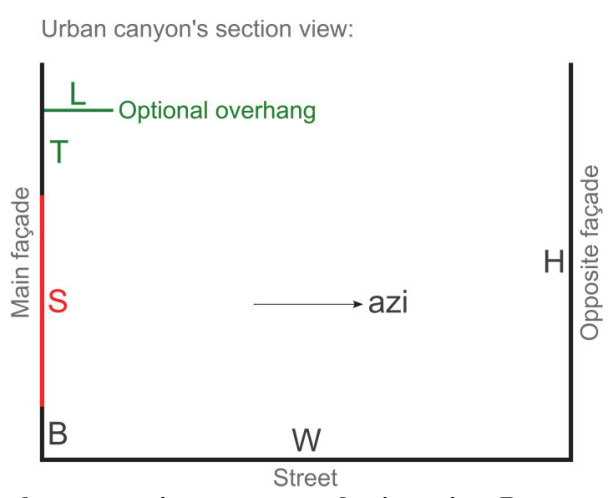

Fig.1: Adjustable parameters defining urban canyon's geometry and orientation. By properly setting parameters B and $\mathrm{S}$, the user can specify on which part of the façade the results have to be computed. Azimuth is counted clockwise from North.

We have chosen a $\sim 100$ meters long street located in the city of Biel in Switzerland. To serve as a case study example throughout this paper, two parts of the main façade are selected for analysis: the façade of the $3^{\text {rd }}$ floor and the shop's vitrine at ground floor (Fig. 2). An optional overhang located above the façade area of interest can also be specified with two additional parameters as shown here for the shop's vitrine.

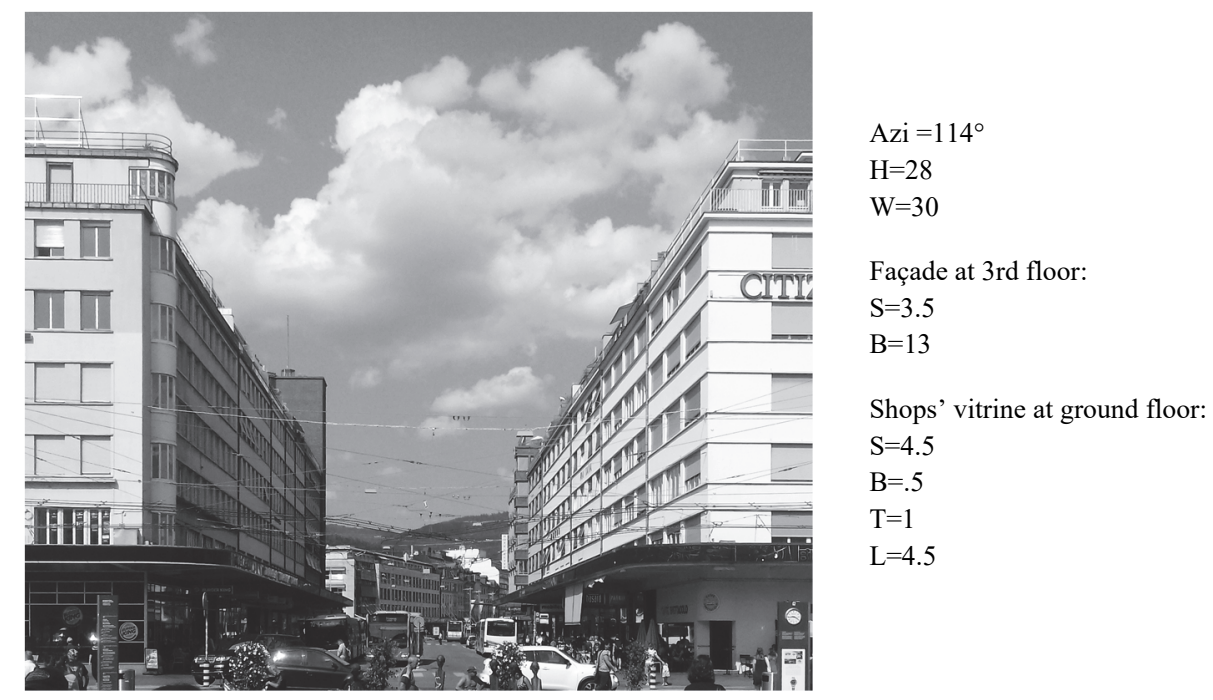

Fig. 2: The urban canyon serving as a case study is located in front of the railway station in Biel, Switzerland. Dimensions shown on the right have been estimated directly from this picture.

Façade and street reflectance values can also be specified to take into account inter-reflections between these surfaces. By default, reflectance values are set to 0.2 . This relatively low value is plausible for two reasons: surface finishes in urban areas are inevitably covered with dust and windows usually occupying large façade fractions behave almost as light traps relatively to the exterior. The calculations are performed assuming purely diffuse reflections with constant reflectance values over the full solar spectrum.

Finally, a location has to be specified. Two options are available to specify a location: either by a latitude or by selecting a specific site from a list of sites for which annual and monthly sky models are available. The sky models have been created based on hourly climatic data obtained from METEONORM software [MET]. More sites will be progressively added to the list in the future.

Figure 3 shows the tool's input page where users specify all these parameters. As seen, by ticking the relevant box, the tool can also produce results on the street level. 


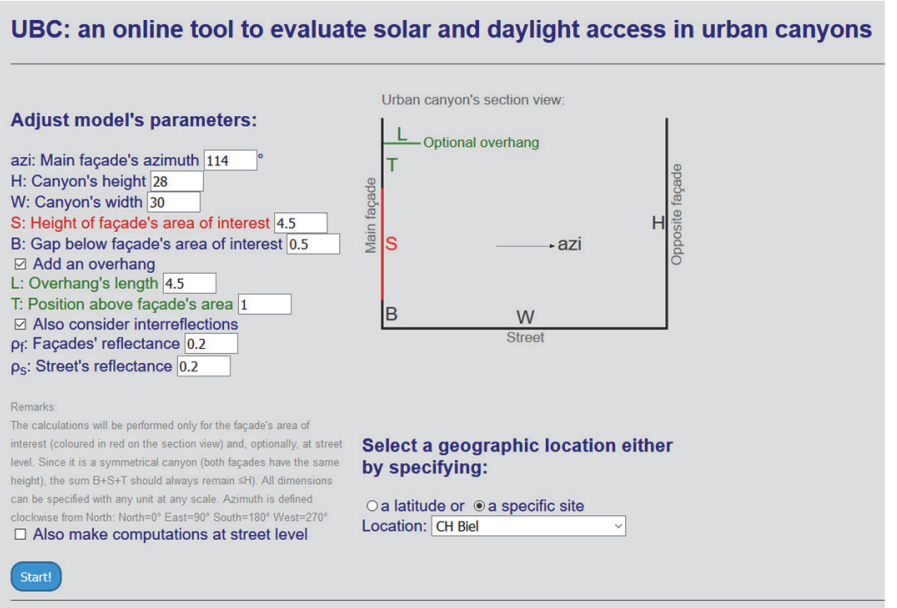

Fig. 3: UBC input page. The parameter values shown here describe the shop's vitrine of our example.

\section{Analyzing sunlight exposure from multi-shading masks}

The sunlight exposure of an area is assessed through its "multi-shading mask". The "multishading mask" is a stereographical projection of the sky vault where the grey level value of each pixel (i.e. from $0=$ black to $1=$ white) indicates the fraction of the considered area (in our case the façade area of interest defined as explained in the preceding section) that has an unobstructed view to the sky in the corresponding direction.

This picture type serves to assess the provision of sunlight through exposure indicators, i..e. WSE and AWSE (Compagnon et al. 2015). Only those hours for which the direct normal irradiance exceeds a threshold of 120 [W/m2] are considered for computing these indicators. This is in line with the "sunshine duration" parameter as defined by (WMO, 2008). In case the location is defined by a latitude only, the potential sunlight exposure WSE is calculated whereas, if a site is selected, the actual sunlight exposure AWSE instead. Since only the latter takes into account the actual climatic conditions it is not surprising that AWSE is much lower than WSE that is computed assuming permanently clear sky conditions. Figure 4 shows the results as presented by the tool.

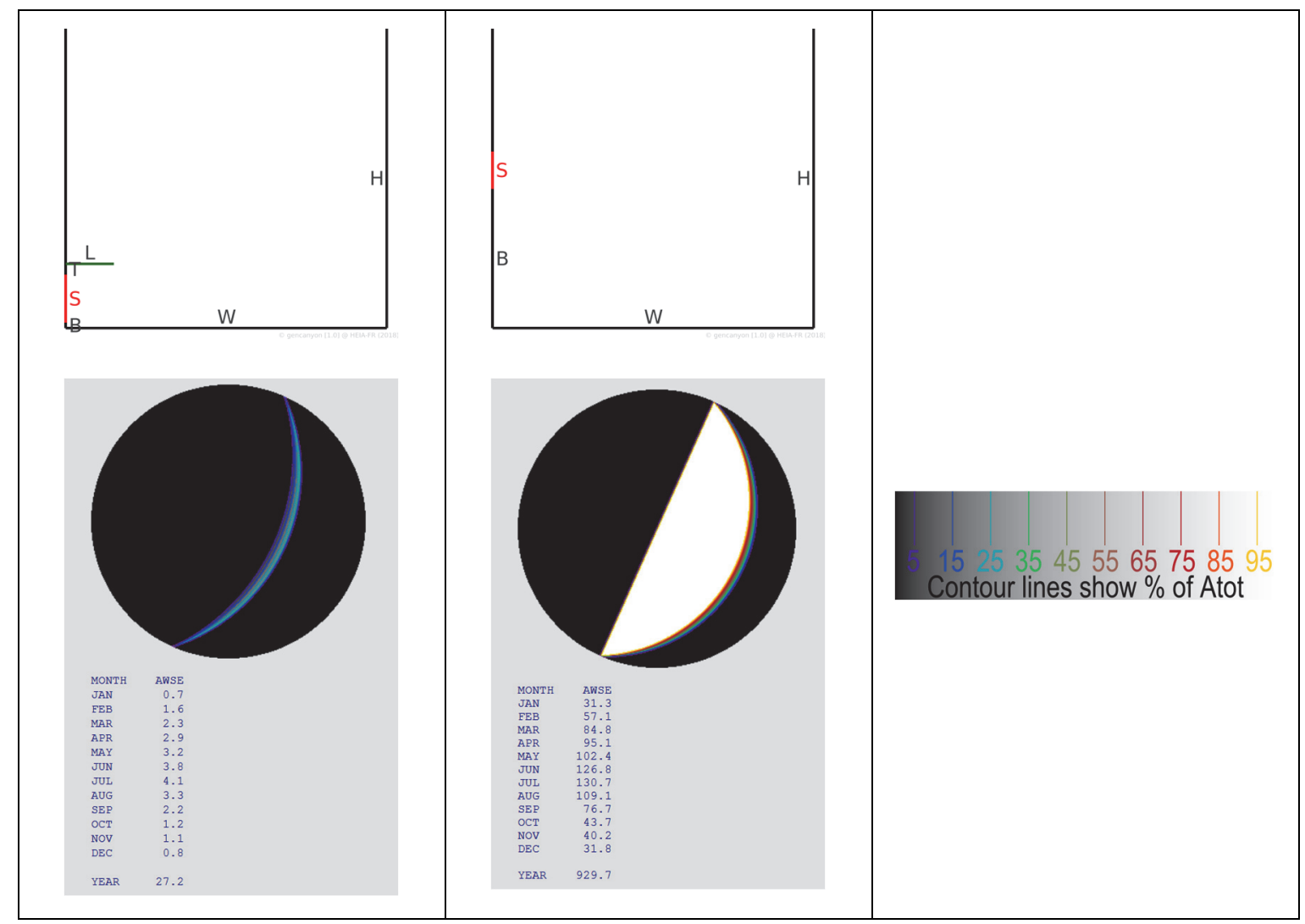

Fig. 4: Sunlight exposure analysis for the shop's vitrine (left) and for the $3^{\text {rd }}$ floor façade (middle). To help visually comparing the multishading masks, coloured iso-contour lines are superimposed (right). 
It is not surprising that, due to the large overhang, the shop's vitrine is almost entirely shaded during the whole year. However, it remains to check to what degree this overhang also decreases vitrine's access to daylight. This aspect is evaluated in the next section.

Even if users are not familiar or even interested in the calculated indicators, they can visually compare the multishading masks with either the sunpath diagram or a representation of the annual sky model for a location. The latter is provided as a stereographic picture of the sky vault showing how the sun and sky radiances are distributed over it (Fig. 5)
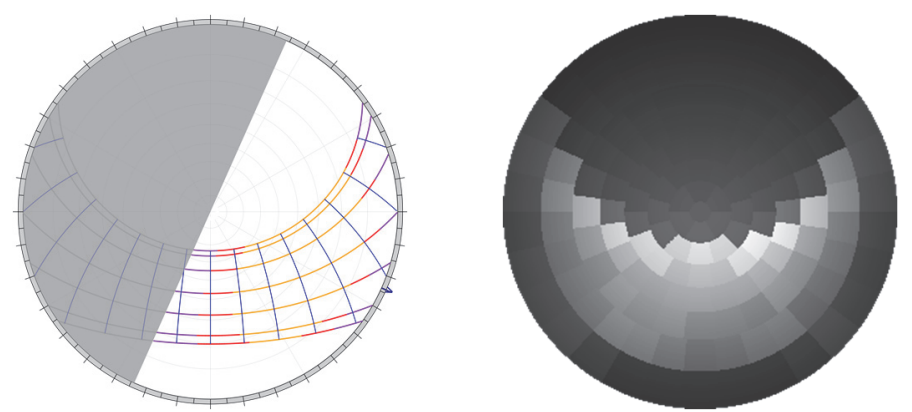

Fig. 5: Left: sunpath diagram for the latitude of Biel. The colours indicate approximate direct irradiance that could potentially reach the considered façade (purple: low $<\sim 200 \mathrm{~W} / \mathrm{m}^{2}$, red: middle $\sim 200$ to $\sim 400 \mathrm{~W} / \mathrm{m}^{2}$, yellow: high $>\sim 400 \mathrm{~W} / \mathrm{m}^{2}$ ). Right: relative distribution of the sky radiance over the sky vault computed from climatic data.

At street level, the multishading mask can serve to check if sunlit and shaded areas are simultaneously provided in adequate fractions. The following indicators are computed (Compagnon et al., 2015): AHOL: number of hours for which the open space (here the street) is overlit (lack of shaded parts); AHOK: number of hours where at least $20 \%$ of shaded or sunlit parts are available (assumed to be benefical for outdoor comfort) and AHOS: number of hours for which the open space is overshaded (lack of sunlit parts). In addition, by superimposing a sunpath diagram, overlit and overshaded periods can be traced in the year (Fig. 6).
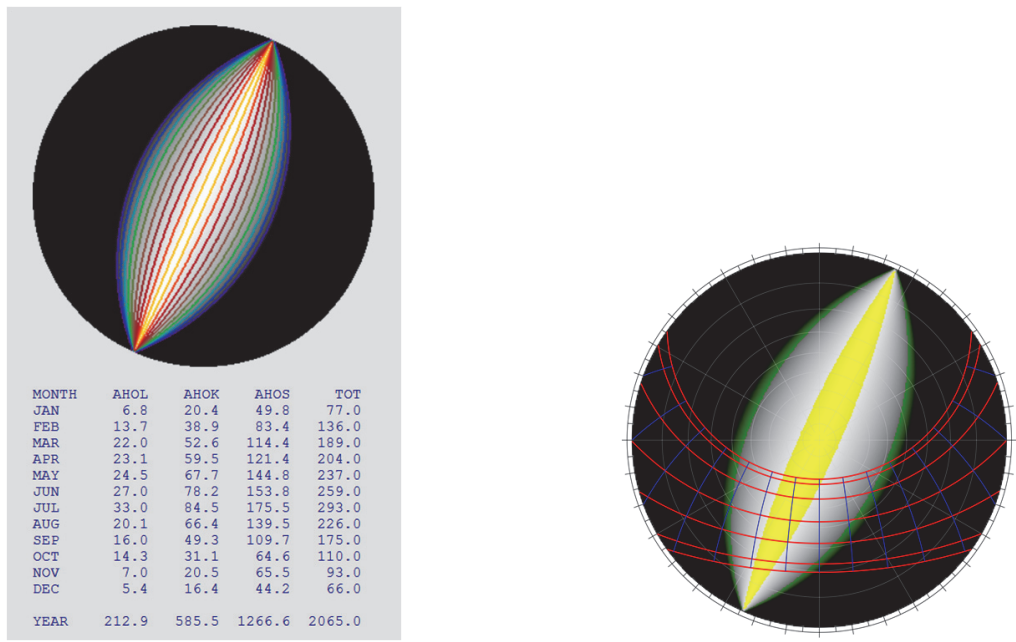

Fig. 6 : Left: multishading mask computed at street level (without any overhang along both façades) and the resulting analysis in term of adequate provision of sunlit and shaded areas. Right: sunpath diagram superimposed on the multishading (overlit hours appear in the yellow coloured region while overshaded hours appear in the green coloured region).

\section{Analyzing irradiation and daylight illuminance from effective envelope area pictures}

An "effective envelope area picture" is again a stereographical projection of the sky vault but where each pixel indicates the total amount (in $\mathrm{m}^{2}$ ) of the considered area that has unobstructed view to the sky in the corresponding direction. More precisely, the amounts stored in each pixel represent projected areas (i.e. the actual façade area is «scaled down» by the cosines between the façade's perpendicular direction and the directions in the sky vault). If this definition may seem complicated, this type of picture can be intuitively interpreted as a representation of how the various directions on the sky vault are visible from an element (e.g. a façade, a street). Furthermore, the Sky View Factor (SVF) and the Average Sky Component (ASC) can be computed from effective envelope area pictures (Fig. 7). 


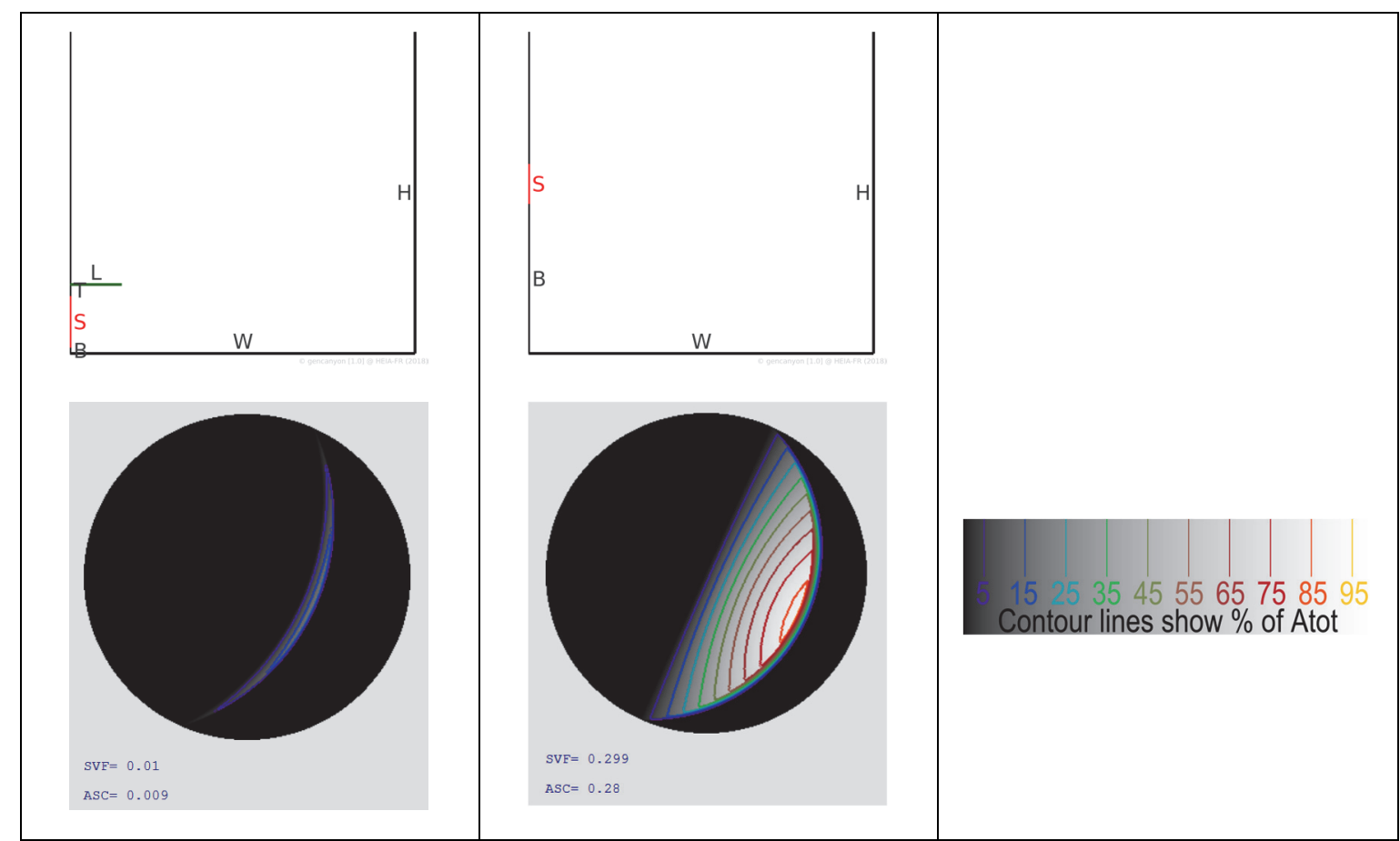

Fig. 7: SVF and ASC calculated for the shop's vitrine (left) and for the $3^{\text {rd }}$ floor façade (middle). To help visually comparing the effective envelope area pictures, coloured iso-contour lines are superimposed (right).

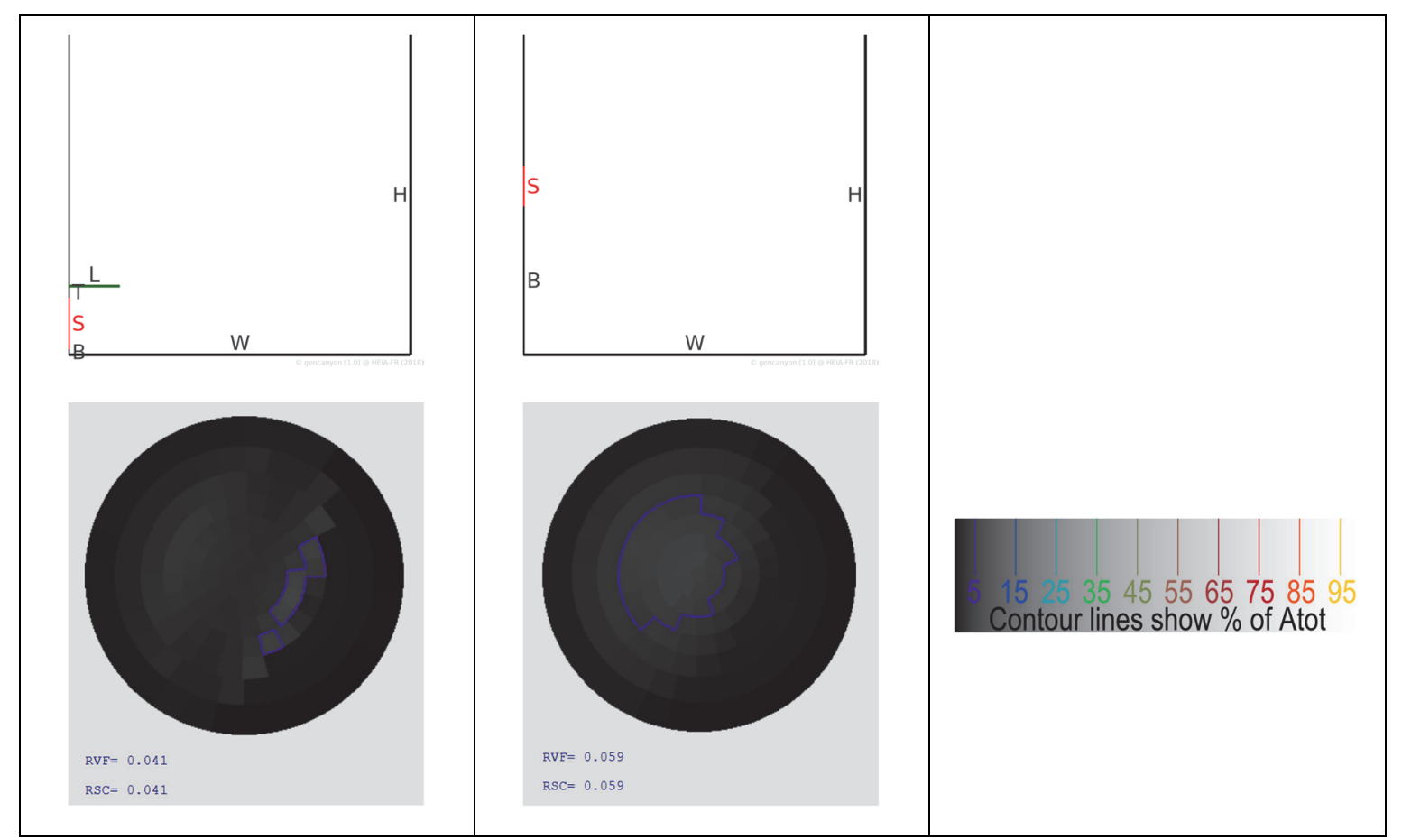

Fig. 8: RVF and RSC calculated for the shop's vitrine (left) and for the $3^{\text {rd }}$ floor façade (middle). To help visually comparing the effective envelope area pictures due to inter-reflections, coloured iso-contour lines are superimposed (right). These results showing that $\mathrm{RVF}=\mathrm{RSC}$ are a pure coincidence.

Here it appears that the shop's vitrine has an ASC value which does not comply with the minimal value of 0.05 recommended by (Littlefair, 2011). After repeating the calculations a few times by altering parameters $\mathrm{L}$ or $\mathrm{T}$, it appears that an ASC value of 0.05 can be reached, for instance, with a shorter overhang (i.e. decreasing length $\mathrm{L}$ to 2.75 ) or by elevating its position (i.e. increasing length $\mathrm{T}$ to 3.1 ).

The inter-reflections occurring between canyon's surfaces can also be taken into account in an effective envelope area picture. In this case, each picture pixel value is calculated differently: for each direction on the sky vault the 
considered area is weighted by a dimensionless factor that accounts for all inter-reflections that contribute to its irradiance. Technically this factor is computed using a particular Radiance program named rtcontrib (Ward, 2010) with the sky vault divided into 145 zones only. The resulting effective envelope area picture can again be intuitively interpreted as a representation of how the various directions on the sky vault are visible from an element. Interestingly, such a picture clearly shows that the whole sky vault contributes to the irradiance of a façade through inter-reflections.

In order to estimate the contribution of inter-reflections to the irradiance or illuminance, two new dimensionless indicators are defined: the Reflected View Factor (RVF) and the Reflected Sky Component (RSC). As shown below, they are both computed very similarly as SVF and ASC respectively:

The global irradiance $\mathrm{G}$ and the illuminance $\mathrm{E}$ of an element are first split into components as:

$$
\begin{aligned}
& \mathrm{G}=\mathrm{G}_{\mathrm{b}}+\mathrm{G}_{\mathrm{d}}+\mathrm{G}_{\mathrm{r}} \\
& \mathrm{E}=\mathrm{E}_{\mathrm{b}}+\mathrm{E}_{\mathrm{d}}+\mathrm{E}_{\mathrm{r}}
\end{aligned}
$$

with $\mathrm{G}_{\mathrm{b}} \mathrm{G}_{\mathrm{d}}$ and $\mathrm{G}_{\mathrm{r}}$ the direct, diffuse from sky and diffuse from inter-reflections irradiance respectively, and $E_{b} E_{d}$ and $E_{r}$ the direct, diffuse from sky and diffuse from inter-reflections illuminance respectively (for convenience, these components will be respectively named in short: direct, diffuse and reflected)

SVF and ASC can be computed as irradiance and illuminance ratios respectively:

$$
\begin{aligned}
& \mathrm{SVF}=\mathrm{G}_{\mathrm{d}} / \mathrm{G}_{\mathrm{dh}} \\
& \mathrm{ASC}=\mathrm{E}_{\mathrm{d}} / \mathrm{E}_{\mathrm{dh}}
\end{aligned}
$$

with $\mathrm{G}_{\mathrm{dh}}$ the diffuse irradiance computed on an unobstructed horizontal plane and $E_{\mathrm{dh}}$ the diffuse illuminance computed on an unobstructed horizontal plane.

Now RVF and RSC can be defined similarly:

$$
\begin{aligned}
& \mathrm{RVF}=\mathrm{G}_{\mathrm{r}} / \mathrm{G}_{\mathrm{dh}} \\
& \mathrm{RSC}=\mathrm{E}_{\mathrm{r}} / \mathrm{E}_{\mathrm{dh}}
\end{aligned}
$$

It is important to note that SVF and RVF are computed under a uniform sky (eq. 3 and 5) while ASC and RSC are computed under a standard CIE overcast sky (eq. 4 and 6).

Figure 8 shows how large the reflected component contribute to the irradiance and daylight illuminance in an urban canyon even with rather low reflectance values (0.2). By comparing Fig. 7 and 8 , it appears that for the shop's vitrine, the reflected component contribute four times more than the sky component!

Finally, effective envelope area pictures can also be combined with sky model pictures in order to compute solar irradiance or irradiation. These figures can be separated into their direct, diffuse and reflected components. The calculation requires three steps: First, a so-called "product picture" is obtained by making a pixel by pixel multiplication between the effective envelope area picture and the sky model picture. Second, the irradiance is computed by summing the values of all pixels contained in the product picture. Last, irradiation is obtained by multiplying the result with the number of hours accounted within the sky model picture. Figure 9 shows how a product picture is produced and how it appears. Note that on this figure, both effective envelope area pictures shown in Figures 7 and 8 have been merged together into a "total effective envelope area picture" that embed the relative contributions of the whole sky vault. The computed irradiations are shown on Figure 10.

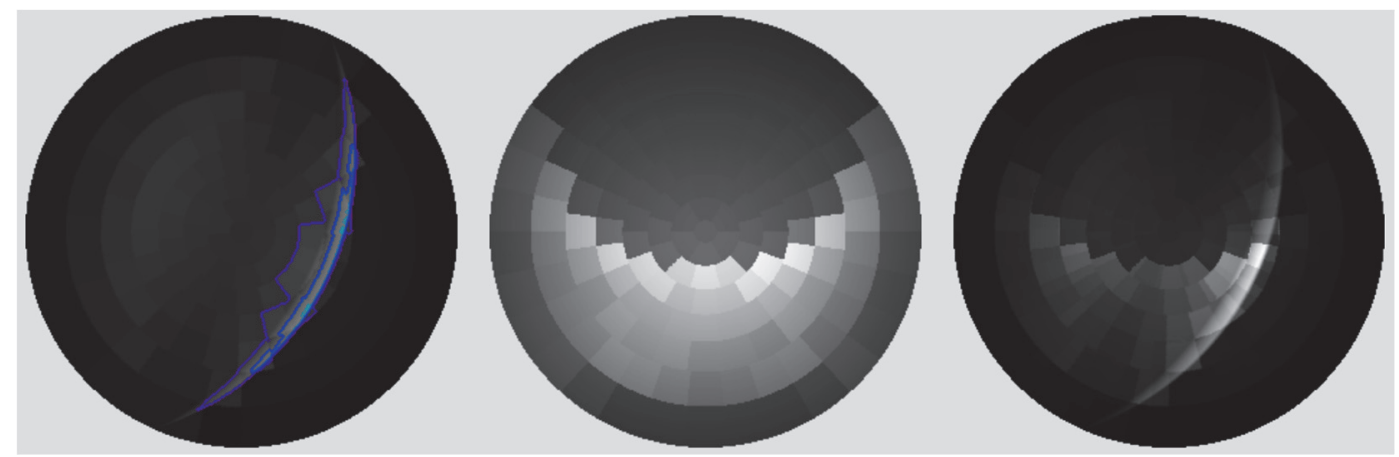

Fig. 9: Left: total effective envelope area picture computed for the shop's vitrine. Middle: annual sky model picture for Biel. Right: product picture from which annual irradiance or irradiation can be computed. 


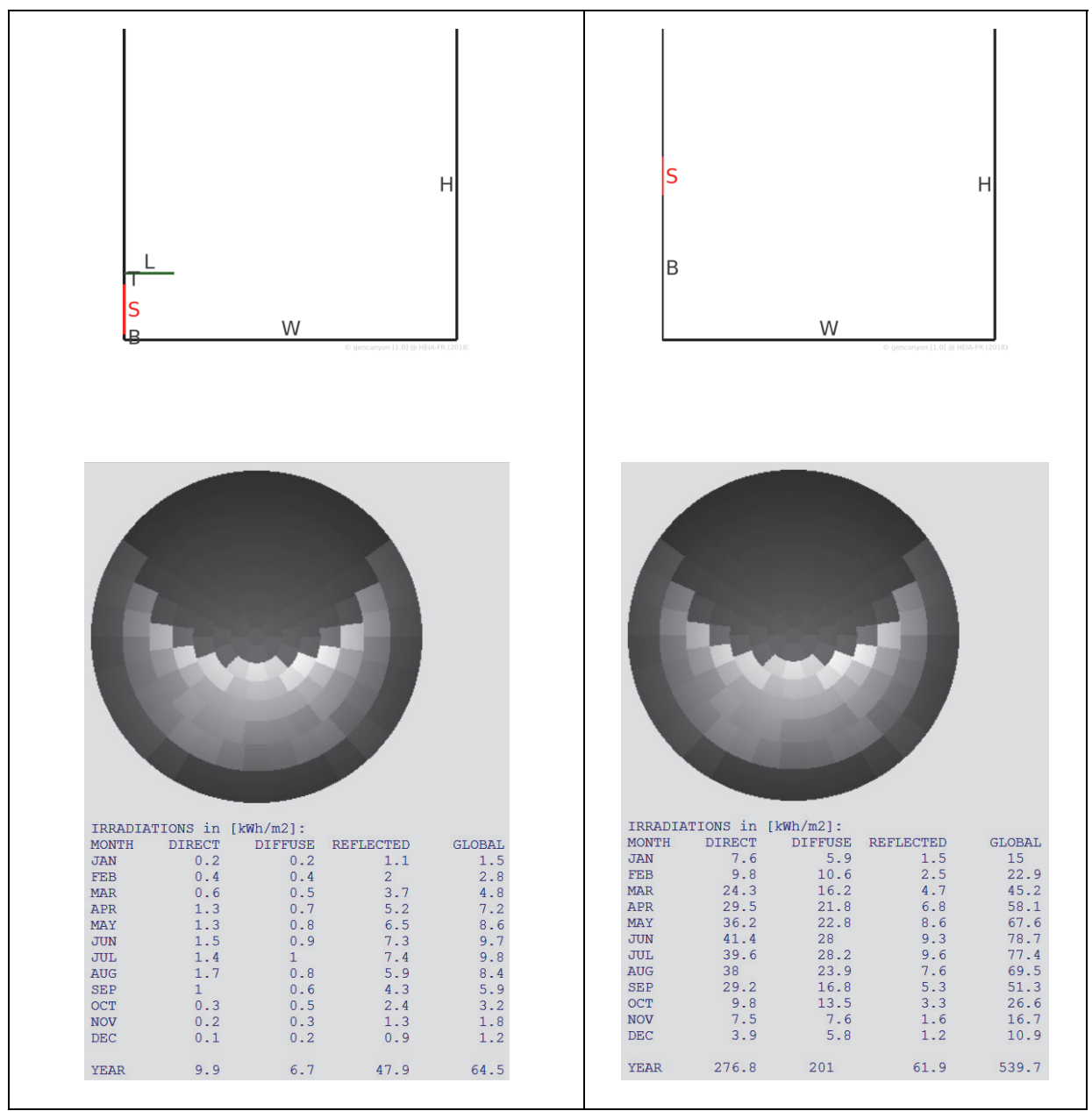

Fig. 10: Irradiations computed for the shop's vitrine (left) and for the $3^{\text {rd }}$ floor façade (right). The annual sky picture for Biel is displayed above the results.

\section{Conclusions}

The [UBC] tool offers a fast way to compute several indicators characterizing solar and daylight access in urban canyons. It uses a calculation method which is based around different types of images facilitating greatly the interpretation of the numerical results. In short, the solar and daylight access of an urban canyon is studied by separating the problem in two parts: a representation of the visibility of the considered surface (part of a façade or the street) from the sky vault (through a multishading mask and an effective envelope area picture) and representations of the climatic context (through a sunpath diagram or sky model pictures). By visually comparing these two representations, the user can understand why some canyon configurations perform better or worse than others do. Since the calculations are performed in just few seconds, the user is encouraged to explore how varying the adjustable parameters can affect the results.

This tool is mainly intended to serve for architectural and urban planning educational purposes. For instance, some of the questions that can be addressed using it are the following:

- Which urban canyon orientation is preferable for a specific location in order to increase the buildings' façades irradiation and enhance active or passive solar applications?

- In a warm climate, which urban canyon orientation offers the maximum shading on façades or on the street level?

- For a façade adjacent to a deep urban canyon, is the shading effect of the opposite façade sufficient to justify not equipping its windows with their own solar shading system? If so, up to which storey level is this valid?

- By how much varies the irradiation when the canyon's façades reflectance is modified?

Beyond the interactive web tool [UBC], the INDALUX open source software package [IDLX] is also available to perform calculations on more complex urban forms. 


\section{Acknowledgements}

The present study was conducted at the smart living lab [SLL] as part of the research project INDALUX funded by the Haute école d'ingénierie et d'architecture de Fribourg [HEIA] and a grant from the ARUP company. The authors would also like to thank the industry partners of the project namely, Paola Longato and Giulio Antonutto from ARUP, Julie Riedo from URBASOL and Céline Girard from CSD ingénieurs.

\section{References}

Chatzipoulka, Ch., Compagnon, R., Kaempf, J., 2018. An Image-Based Method to Evaluate Solar and Daylight Potential in Urban Areas. In: 2018 Proceedings of the Symposium for Architecture and Urban Design, pp. 337-344. Available at: http://simaud.org/proceedings/ [Accessed 27 August 2018]

Compagnon, R., Antonutto, G., Longato, P., Rotsch, A., 2015. Assessing daylight and sunlight access in the built environment: A new tool for planners and designers. In: Proceedings PLEA2015 - 31st Conference on Passive and Low Energy Architecture. Available at: https://multidoc.heia-fr.ch/record/2120 [Accessed 28 August 2018]

Compagnon, R., 2014. Evaluating solar irradiance on urban sites by superimposing Radiance pictures. In: $13^{\text {th }}$ International Radiance workshop. Available at: https://www.radiance-online.org/community/workshops/2014london [Accessed 5 September 2018]

WMO, 2008. Guide to Meteorological Instruments and Methods of Observation, 7th edition, World Meteorological Organization, Geneva, Switzerland.

Littlefair, P., 2011. Site layout planning for daylight and sunlight, a guide to good practice, BR 209 2nd edition. Building Research Establishment, Garston, UK.

Ward, G., 2010. The Radiance rtcontrib program. In: $9^{\text {th }}$ International Radiance workshop. Available at: https://www.radiance-online.org/community/workshops/2010-freiburg [Accessed 7 September 2018]

\section{Web references}

[HEIA] Haute école d'ingénierie et d'architecture de Fribourg: https:/heia-fr.ch [Accessed 29 August 2018]

[IBIC] Image based irradiation \& irradiance calculations: https://phybat.heia-fr.ch/ibic/ [Accessed 28 August 2018] [IDLX] INDALUX software package: https://phybat.heia-fr.ch/idlx/ [Accessed 6 September 2018]

[MET] Meteonorm; Irradiation data for every place on Earth: http://www.meteonorm.com/ [Accessed 6 September 2018]

[RAD] Radsite: https://www.radiance-online.org/ [Accessed 5 September 2018]

[SLL] smart living lab: a research and development center for the built environment of the future: http://smartlivinglab.ch [Accessed 29 August 2018]

[UBC] UBC: an online tool to evaluate solar and daylight access in urban canyons: https://phybat.heia-fr.ch/ubc/ [Accessed 29 August 2018] 